\title{
Short-term outcome after microdiscectomy for lumbar disc herniation - a single centre study
}

\author{
Bartłomiej Kulesza ${ }^{1, A, C-D, F \oplus}{ }^{\text {, Paweł Szmygin }}{ }^{1, B, D-E \oplus}$, Paweł Krukow ${ }^{2, C-D \oplus}{ }^{\text {, Marek Mazurek }}{ }^{1, D-E} \oplus$, \\ Jacek Kulesza ${ }^{3, A, F} \oplus$ \\ 1 Department of Neurosurgery and Paediatric Neurosurgery, Medical University, Lublin, Poland \\ 2 Department of Clinical Neuropsychiatry, Medical University, Lublin / Independent Public Clinical Hospital No. 1, Lublin, \\ Poland \\ ${ }^{3}$ Department of Neurosurgery, Specialist Hospital, Sandomierz, Poland \\ A - Research concept and design, B - Collection and/or assembly of data, C - Data analysis and interpretation, \\ $D$ - Writing the article, $E$ - Critical revision of the article, $F$ - Final approval of article
}

\begin{abstract}
Kulesza B, Szmygin P, Krukow P, Mazurek M, Kulesza J. Short-term outcome after microdiscectomy for lumbar disc herniation - a single
\end{abstract} center study. J Pre-Clin Clin Res. 2021; 15(1): 1-4. doi: 10.26444/jpccr/132683

\begin{abstract}
Introduction. Lumbar disc herniation (LDH) is a common cause of back pain and leg pain. For more than 60 years, standard discectomy by fenestration has been used to treat LDH. In his study, three commonly used scales were used to assess the outcome after microdiscectomy, such as the Low Back Pain Rating Scale (LBPRS), Oswestry Disability Index (ODI) and the Visual Analogue Scale (VAS). To the best of the authors' knowledge, this is the first study analyzing treatment results at 3 months after microdiscectomy.

Materials and method. During almost 5 years, a total of 327 patients underwent microdiscectomy operations for single level disc disease. Of these, 286 patients were available for 3-mounth follow-up. All patients were operated on at the Neurosurgery Department in the Specialist Hospital in Sandomierz, Poland. Before surgery and 3 months after burgery, all patients were asked to complete LBPRS, ODI and VAS scales. The statistical analysis used was $\bigotimes p 2$, the effect size indicator for ANOVA.

Results. Significant improvement was observed in all scales used 3 months after surgery.

Conclusions. There are new, minimally invasive percutaneous techniques available, such as percutaneous laser disc decompression and intradiscal injection of radiopaque gelified ethanol. There are also trials with platelet-rich plasma or mesenchymal stem cells injected into the disc, aimed at the restoration of healthy disc properties. The hypothesis that metabolic products of bacteria propionibacterium acnes can contribute to disc degeneration inspired attempts at antibiotic therapy This study was conducted on a large group of patients and confirmed that discectomy is the recommended method of surgery which produces good treatment results in 3-mounths follow-up.
\end{abstract}

\section{Key words}

low back pain, lumbar disc herniation, microdiscectomy

\section{INTRODUCTION}

Low back pain is a common problem in industrialized societies [1]. Lumbar disc herniation (LDH) is a common cause of back pain and leg pain [2]. For more than 70 years, standard discectomy by fenestration has been used worldwide to treat lumbar disc herniation [3]. Despite the emergence of new and often less invasive treatment methods, standard discectomy is the preferred technique for the surgical treatment of disc herniation, recognized by many surgeons for producing good results [4]. Surgery treatment is usually offered to patients with persisting pain in the lower back, with or without radiating to the leg despite conservative treatment, difficult to control pain or acute paresis, including cauda equine syndrome $[5]$.

Three commonly used scales were used in this study to assess outcomes following therapeutic interventions for low back pain. The Low Back Pain Rating Scale (LBPRS) developed by Manniche et al., consists of three clinical components: pain (0-60 points), disability ( $0-30$ points) and physical

Address for correspondence: Bartłomiej Kulesza, Department of Neurosurgery and Paediatric Neurosurgery, Medical University, Strumykowa 96, 20-855, Lublin, Poland E-mail: kuleszabartek88@gmail.com

Received: 06.12.2020; accepted: 22.01.2021; first published: 12.02.2021 impairment ( $0-40$ points). The Oswestry Disability Index (ODI) is an indicator calculated on the basis of the Oswestry Low Back Pain Questionnaire used to assess disability due to low back pain. The Visual Analogue Scale (VAS) was the last scale used $[6,7]$.

The aim of the study was to measure clinical outcomes at three months following first time surgery of single-level lumbar microdiscectomy. To the best of the authors knowledge, this is the first study analyzing treatment results at 3 months after microdiscectomy.

\section{METHOD AND RESULTS}

Between September 2014 - January 2019, a total of 327 patients were operated on by microdiscectomy for single level disc disease using the fenestration method. Of these, 286 patients were available for 3-mounths follow up. All patients were operated on at the Neurosurgery Department in the Specialized Hospital of the Holy Spirit in Sandomierz, Poland. Inclusion criteria were 1) radicular pain lasting for a minimum of 21 days, 2) an MRI finding of intervertebral disc extrusion or sequester, 3 ) at least one specific physical finding (a positive straight leg raising test $<60^{\circ}$, muscle 
weakness, weakness in tendon reflex, or a dermatomal sensory change). Patients who had previously undergone lumbar spine surgery, extra-foraminal disc herniation, or coexisting spinal degenerative spondylolisthesis and/or scoliosis, were excluded.

Before surgery and three months after surgery, All patients were asked to complete LBPRS, ODI and VAS scales. Significant improvement was observed in all scales used three months after surgery (Tab. 1).

Table 1. Minimum, maximum and median values in the scales

\begin{tabular}{llcccccc}
\hline Scale & \multicolumn{3}{c}{$\begin{array}{c}\text { Before } \\
\text { surgery }\end{array}$} & \multicolumn{3}{c}{$\begin{array}{c}\text { months after } \\
\text { surgery }\end{array}$} \\
\cline { 2 - 8 } & & Min & Max & Median & Min & Max & Median \\
\hline $\begin{array}{l}\text { Low Back } \\
\text { Pain Rating } \\
\text { Scale }\end{array}$ & Pain & 0 & 82 & 31 & 0 & 52 & 12,5 \\
\cline { 2 - 8 } & Disability & 2 & 71 & 19 & 0 & 86 & 9 \\
\cline { 2 - 8 } & physical impairment & 2 & 37 & 17 & 0 & 24 & 4 \\
\cline { 2 - 8 } & maximum points & 13 & 116 & 68 & 0 & 146 & 30,5 \\
\hline Oswestry Disability Index & 0 & 94 & 44 & 0 & 66 & 20 \\
\hline Visual & back pain & 0 & 10 & 5 & 0 & 10 & 2 \\
\cline { 2 - 8 } $\begin{array}{l}\text { Analogue } \\
\text { Scale }\end{array}$ & leg pain & 0 & 10 & 5 & 0 & 10 & 0
\end{tabular}

Characteristics of the group. The participants included 149 males (52.1\%) and 137 females (47.9\%). The age of the patients ranged from $18-79$ years with the median age of 47 years. Most patients were operated on at level L4-L5 (154 patients - 53.9\%), level L5-S1 (102 patients - 35.8\%), $23(0.9 \%)$ patients at level L3-L, and $7(0.4 \%)$ patients at level L2-L3. The median length of symptoms before surgery lasted nine months, a maximum of 24 years and a minimum of 21 days.

Statistical analysis. The statistical analysis used was $\eta_{\pi}^{2}$, the effect size indicator for ANOVA with repeated measurements. Effect size is a measure of the extent of variation in the distribution of the studied populations. All $\eta_{\pi}^{2}<0.14$ are classified as 'large effect', i.e. very large differences (or experimental effects). In the obtained results, all effects were very large, which means that the results of individual scales before and after the operation differed not only significantly, but to a large extent their distributions had very few points in common. Of all the measurements examined, the impact of surgery in LBPRS scale physical impairment was the most positive $\left(\eta_{\pi}^{2}=0.67\right)$.

\section{RESULTS}

The median LBPRS-maximum points before surgery was 68 points and after surgery 30.5 ; the difference was statistically significant $\mathrm{p}=0.0001$. Similarly, all components of the LBPRS scale before and after surgery were associated with statistical significant differences $\mathrm{p}=0.0001$ (Fig. 1).

Median in the ODI scale before surgery was 44 points, and three mouths after surgery decreased to 20 points $(\mathrm{p}=0.0001)$ (Fig. 2).

The median VAS scale before surgery was 5 points for back and leg pain, with significant improvement $(\mathrm{p}=0.0001)$ after surgery, with a median of 2 and 0 , respectively.

\section{DISCUSSION}

There are several possible treatments for lumbar discopathy. Conservative improvement is expected in pain in $90 \%$ of patients [8]. However, surgical as well as conservative treatment had good long-term treatment outcome for sciatica symptoms in patients with lumbar disc herniation. Compared to conservative treatment, surgical treatment relieved back pain faster, although no advantage was seen in any treatment after three months. [9].

The findings of this study confirm the well-established observation that discectomy is a safe and effective treatment method in lumbar discopathy with sciatic pain. Although success-rates as high as $88-97 \%$ have been reported for this procedure, more realistic outcomes, as measured by patientreporting scales, range from $75-80 \%$ [10]. Studies show that decompression of the neural structures improves not only the quality of life, but also significantly reduces depressive symptoms [11]. 76\% patients operated on for lumbar disc herniation are able to return to work in one year [12]. 4\% of patients experience deterioration of functional status following the surgery. The correlates of deterioration are: long duration of pain and low ODI (higher function) prior to surgery [13].

Since the introduction of lumbar discectomy by Mixter and Barr in 1934, modifications of the technique have been proposed, with increasing significance of minimally invasive surgery. A meta-analysis of several studies with a total 929 patients have shown that the effects of microdiscectomy and sequestrectomy are similar in the reherniation rate, hospitalization time and postoperative pain [14]. However, studies with prolonged follow-up times show that 25\% may need a second operation at the same lumbar level [15]. SPORT study and previous reports have demonstrated that older age was associated with lower number of reoperations, possibility due to surgeons' reluctance to indicate reoperations for older patients [16]. The cumulative risk of leg pain recurrence within threeyears after surgery is $45 \%$, but it is substantially lower if the pain resolves completely immediately after the initial surgery [17].

In the current study, the incidence of disc herniation at particular lumbar levels reflects the typical distribution, L4/ L5 and L5/S1 being the most common in over $90 \%$ of cases, which is confirmed by other studies $[2,5,12]$.

New, minimally invasive percutaneous techniques usually do not require general anaesthesia and hospitalization, thus reducing healthcare costs compared with surgery. They include percutaneous laser disc decompression (PLDD) and intradiscal injection of radiopaque gelified ethanol $\left(\right.$ DiscoGel $\left.{ }^{\oplus}\right)$. The first technique aims to indirectly reduce the pressure of the herniation on the nerve root through vaporization of a small volume of nucleus pulposus by laser energy [18]. A randomized/prospective trial of 115 patients demonstrated that PLDD render similar pain-relieving effect to standard microdiscectomy, although the latter is associated with faster recovery and fewer reoperations (38\% for PLDD vs. $16 \%$ microdiscectomy) [19]. DiscoGel ${ }^{\circledR}$ is believed to work according to the similar principle - ethanol causes local necrosis of the nucleus pulposus decreasing the intradiscal pressure which leads to retraction of the herniation [20].

Volpentesta et al. report significant pain reduction, both immediately after the procedure and in 6,12 and 18 months' follow-up in $90 \%$ patients treated with Discogel $^{\circledast}$ 


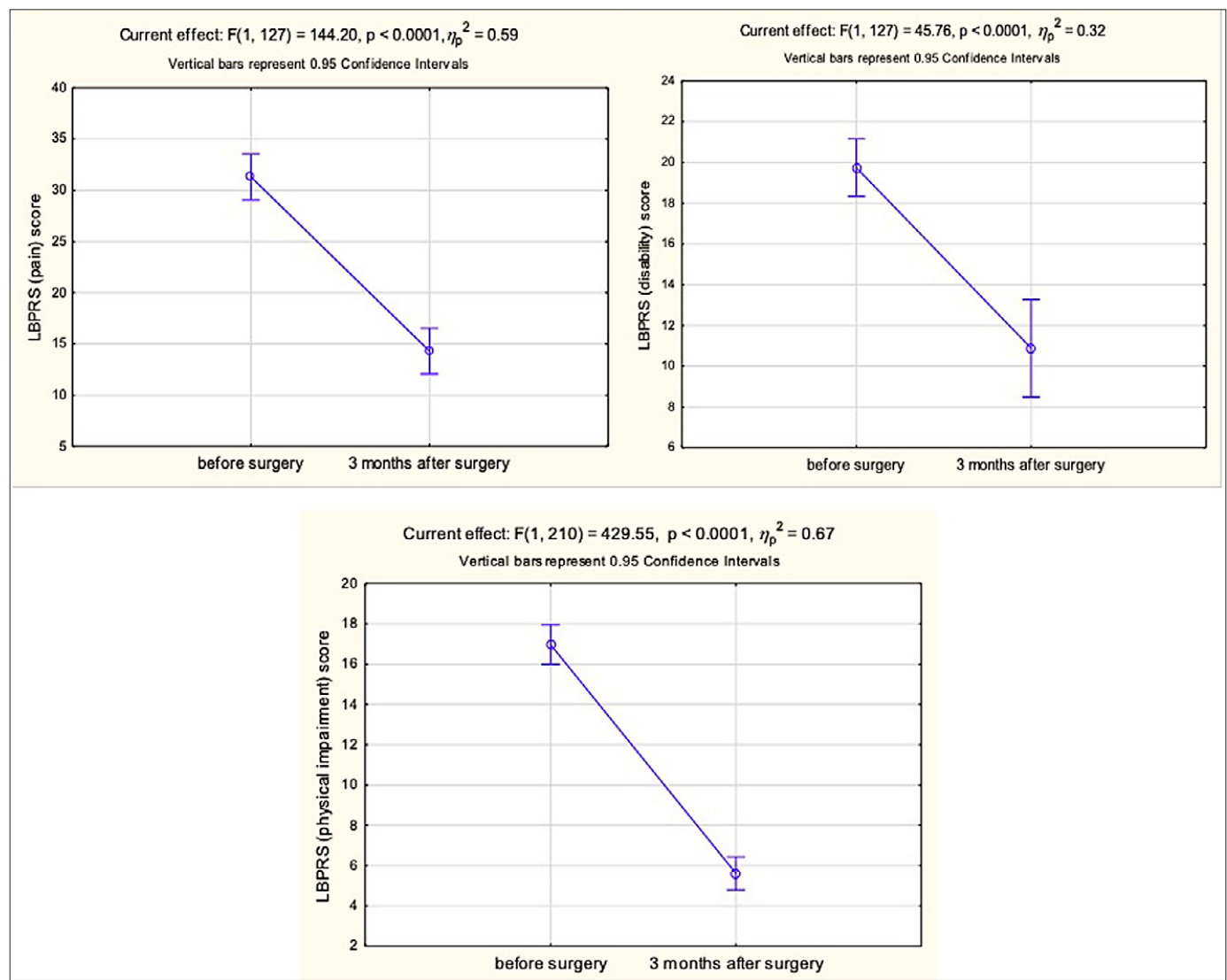

Figure 1. LBPRS scale before and 3-months after surgery

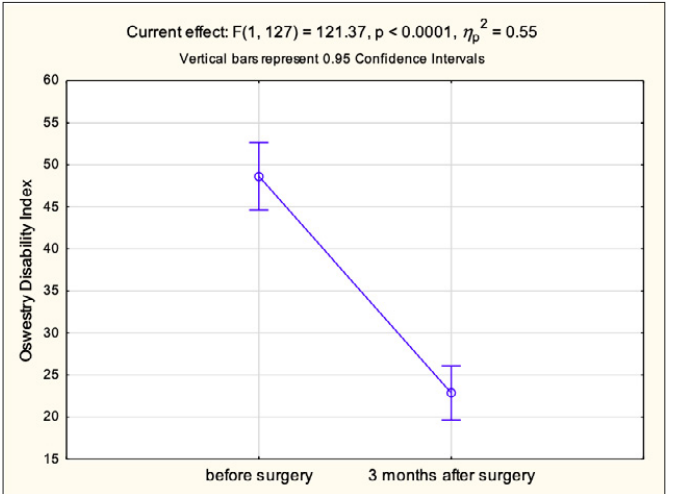

Figure 2. ODI scale before and 3-months after surgery for lumbar disc herniation [21]. Apart from the relatively new Discogel ${ }^{\oplus}$, numerous agents have been tested previously for chemonucleolysis: chymopapain and matrix metalloproteinase [22]. These substances also contribute to the attraction of macrophages, dessication and significant reduction of the volume of herniated disc material [23]. The investigated factors correlating with positive outcome for all types of chemonucleolysis are: dominance of leg over the back pain, posterolateral rather than generalized, broad-base disc herniation, younger age, lack of bony spurs, and shorter duration of symptoms [24].

The variety of lumbar discopathy treatment strategies derives from the multitude of theories about the pathogenesis of radicular pain. Decompression techniques
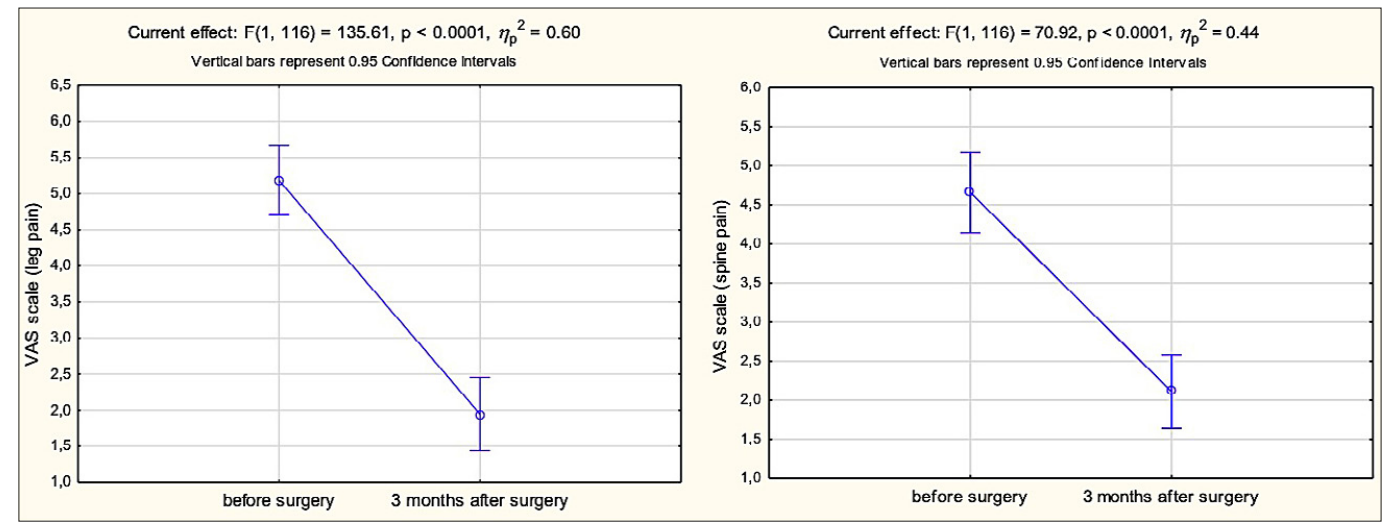

Figure 3. VAS scale before and 3-months after surgery 
(endoscopic, micro- or open-discectomy, different types of chemonucleolysis, intraspinous process devices) address the mechanical pressure exerted by the herniated disc on the nerve root exiting the intervertebral foramen. Trials with platelet-rich plasma or mesenchymal stem cells injected into the disc seek to restore the balance between the catabolic, pro-inflammatory (interleukin-1 [25] and anabolic mediators (insulin-like growth factor, fibroblast growth factor, bone morphogenic protein $[26,27,28])$. The aim is the restoration of healthy disc properties and preventing the chemical irritation of the neural structures.

The above-mentioned non-surgical methods are certainly very appealing to many patients, yet discectomy remains the most efficient and wide-spread procedure for discopathyrelated lumbar pain resistant to conservatory treatment.

\section{CONCLUSIONS}

The 286 patients treated with lumbar discectomy analyzed in the current study significantly improved after the surgery. The Low Back Pain Rating Scale (LBPRS) and the Oswestry Disability Index (ODI) are relevant and generally accepted tools for evaluating patients pre- and post-operatively. Although there are new, minimally invasive percutaneous techniques such as percutaneous laser disc decompression and intradiscal injection of radiopaque gelified ethanol, there are also trials with platelet-rich plasma or mesenchymal stem cells injected into the disc, aimed at the restoration of healthy disc properties. The hypothesis that the metabolic products of low-virulence anaerobic bacteria propionibacterium acnes can contribute to disc degeneration inspired antibiotic therapy attempts.

This study was conducted on a large group of patients and confirms that discectomy is the recommended method of surgery and produces good treatment results in 3-months follow up. Despite the emergence of new, often less invasive treatment methods, standard discectomy is the preferred technique for the surgical treatment of disc herniation.

The limitations of the study were no longer follow up and no analysis of complications or failures of treatment.

\section{REFERENCES}

1. Hartvigsen J, Hancock MJ, Kongsted A, et al. What low back pain is and why we need to pay attention. Lancet 2018; published online March 21. http://dx.doi.org/10.1016/S0140-6736(18)30480-X

2. Ruan W, Feng F, Liu Z, et al. Comparison of percutaneous endoscopic lumbar discectomy versus open lumbar microdiscectomy for lumbar disc herniation: A meta-analysis. Int J Surg. 2016; 31: 86-92.

3. Hamawandi SA, Sulaiman II, Al-Humairi AK. Open fenestration discectomy versus microscopic fenestration discectomy for lumbar disc herniation: a randomized controlled trial. BMC Musculoskelet Disord. 2020; 21(1): 384. Published 2020 Jun 15. doi: 10.1186/s12891-020-03396-x

4. Kreiner DS, Hwang SW, Easa JE, et al. An evidence-based clinical guideline for the diagnosis and treatment of lumbar disc herniation with radiculopathy. Spine J. 2014; 14: 180-91.

5. Deyo RA, Mirza SK. CLINICAL PRACTICE. Herniated Lumbar Intervertebral Disk. N Engl J Med. 2016; 374(18): 1763-72.

6. Chiarotto A, Maxwell LJ, Ostelo RW, Boers M, Tugwell P, Terwee CB (2018) Measurement properties of visual analogue scale, numeric rating scale, and pain severity subscale of the brief pain inventory in patients with low back pain: a systematic review. J Pain Off J Am Pain Soc. https://doi.org/10.1016/j.jpain.2018.07.009

7. Brodke DS, Goz V, Lawrence BD, Spiker WR, Neese A, Hung M. Oswestry Disability Index: a psychometric analysis with 1,610 patients. Spine J. 2017; 17: 321-327.

8. Bailey CS, Rasoulinejad P, Taylor D, et al. Surgery versus conservative care for persistent sciatica lasting 4 to 12 months. N Engl J Med 2020; 382: $1093-102$

9. Gugliotta M, Costa BR, Dabis E, et al. Surgical versus conservative treatment for lumbar disc herniation: a prospective cohort study. BMJ Open 2016: 1-7. https://doi.org/10.1136/bmjopen-2016-012938

10. Asch HL, Lewis PJ, Moreland DB, et al. Prospective multiple outcomes study of outpatient lumbar microdiscectomy: should 75 to $80 \%$ success rates be the norm? J Neurosurg. 2002; 96: 34-44.

11. Tharin S, Mayer E, Krishnaney A. Lumbar microdiscectomy and lumbar decompression improve functional outcomes and depression scores. Evid Based Spine Care J. 2012; 3: 65-66.

12. Weinstein JN, Lurie JD, Tosteson TD, et al. Surgical vs nonoperative treatment for lumbar disk herniation: the Spine Patient Outcomes Research Trial (SPORT) observational cohort. JAMA 2006; 296: 2451 2459.

13. Solberg TK, Nygaard OP, Sjaavik K, et al. The risk of "getting worse" after lumbar microdiscectomy. Eur Spine J. 2005; 14: 49-54.

14. Huang T, Tian Z, Li M, et al. Sequestrectomy versus microdiscectomy in the treatment of lumbar disc herniation: a meta-analysis. Int J Clin Exp Med. 2015; 8(05): 7261-7269.

15. Du J, Shue J, Evangelisti G, et al. Microdiscectomy for the Treatment of Lumbar Disc Herniation: An Evaluation of Reoperations and Long-Term Outcomes. Evidence-Based Spine-Care Journal 2014; 05(02): 077-086.

16. Leven D, Passias PG, Errico TJ, et al. Risk Factors for Reoperation in Patients Treated Surgically for Intervertebral Disc Herniation. The Journal of Bone and Joint Surgery-American Volume 2015; 97(16): $1316-1325$.

17. Koerner JD, Glaser J, Radcliff K. Which Variables Are Associated With Patient-reported Outcomes After Discectomy? Review of SPORT Disc Herniation Studies Clinical orthopaedics and related research 2015; 473: 2000-6.

18. Ren L, Guo H, Zhang T, et al. Efficacy evaluation of percutaneous laser disc decompression in the treatment of lumbar disc herniation. Photomed Laser Surg 2013; 31: 174-8.

19. Brouwer PA, Brand R, van den Akker-van Marle ME, et al. Percutaneous laser disc decompression (PLDD) versus conventional microdiscectomy in sciatica: A randomized controlled trial. Spine J. 2015; 15: 857-65.

20. Theron J, Guimaraens L, Casasco A. Percutaneous treatment of lumbar intervertebral disk hernias with radiopaque gelified ethanol: a preliminary study. J Spinal Disord Tech. 2007; 20: 526-532.

21. Volpentesta G, De Rose M, Bosco D, et al. Lumbar percutaneous intradiscal injection of radiopaque gelified ethanol ("Discogel") in patients with low back and radicular pain. J Pain Relief 2014; 3: 145.

22. Haro H, Nishiga M, Ishii D, et al. Experimental chemonucleolysis with recombinant human matrix metalloproteinase 7 in human herniated discs and dogs. Spine J. 2014; 14(7): 1280-1290.

23. Haro H, Komori H, Kato T, et al. Experimental studies on the effects of recombinant human matrix metalloproteinases on herniated disc tissues--how to facilitate the natural resorption process of herniated discs. J Orthop Res. 2005; 23(2): 412-9.

24. Kim YS, Chin DK, Yoon DH, et al. Predictors of successful outcome for lumbar chemonucleolysis: analysis of 3000 cases during the past 14 years. Neurosurgery. 2002; 51(5 Suppl): S123-S128.

25. Masuda K. Biological repair of the degenerated intervertebral disc by the injection of growth factors. Eur Spine J. 2008; 17(Suppl 4): 441-451.

26. Xu Z, Zhou X, Chen G. Expression and Mechanism of Interleukin 1 (IL-1), Interleukin 2 (IL-2), Interleukin 8 (IL-8), BMP, Fibroblast Growth Factor 1 (FGF1), and Insulin-Like Growth Factor (IGF-1) in Lumbar Disc Herniation. Med Sci Monit. 2019 Feb 04; 25: 984-990.

27. May RD, Frauchiger DA, Albers CE, Benneker LM, Kohl S, Gantenbein B. Inhibitory effects of human primary intervertebral disc cells on human primary osteoblasts in a co-culture system. Int J Mol Sci. 2018; 19: 1195 .

28. Amin RM, Andrade NS, Neuman BJ. Lumbar Disc Herniation. Current Reviews in Musculoskeletal Medicine 2017; 10: 1-10. 